\title{
Advantages and Suggestions of the Construction of Garden City for Chengdu
}

\author{
Jianping Liu
}

College of Law, Sichuan Agricultural University, Ya’an, 625000, China

Keywords: Garden city, Ecological value, City planning

\begin{abstract}
After Chengdu proposed to build a modern garden city in the world, it also proposed to build a "beautiful and livable garden city" in 2018. In theory, the garden city is a new concept and the theoretical system is not perfect. In practice, the garden city is still in the early stage of exploration, only referring to the experience of pastoral city, forest city, garden city and other cities to explore and promote. In the process of building a garden city, Chengdu has its unique natural and cultural advantages, which lay a solid foundation for building a garden city. It is imperative for Chengdu to do a good job in scientific and rational urban planning, build a garden city index system, highlight the ecological value of the city, and build an ecological community of mountains, rivers, forests and cities.
\end{abstract}

\section{Connotation of Garden City}

In February 2018, when General Secretary Xi Jinping visited the Tianfu New Area in Chengdu, he put forward the concept of "garden city" for the first time, and pointed out that the characteristics of garden city should be highlighted and ecological value should be considered. The "ecological" element is the focus of the concept of Garden city. The concept of garden city put forward by the general secretary has absorbed the essence of the theories of garden city, ecological city, green city, landscape city and garden city. It not only conforms to the law of urban development, but also helps to solve the problem of "urban disease", but also meets the people's growing needs for a better life and promotes regional core competition. Strength is a brand-new concept and urban development model in the new era of socialism and the new stage of ecological civilization, with extremely profound connotation.

On May 11, 2018, Tianfu Garden city Research Institute was formally established in Tianfu New Area, Chengdu. Relevant experts discussed the connotation of Garden city and its construction path, which laid a theoretical foundation for Chengdu to practice the "beautiful and livable Garden city". Wu Zhiqiang, academician of the Chinese Academy of Engineering and vice president of Tongji University, has been widely accepted by all walks of life for his analysis of the connotation of "garden city". He pointed out that garden city is not a simple addition of park and city, but an effective combination of public, park, city and city, and "public" represents the public, emphasizing the function of public communication. "City" stands for life, stresses human settlement and life, and "City" stands for production, stresses industrial and economic activities. In short, it is "one public and three generations". "Public" means public participation. It means ecology, life and production. The purpose of Garden city is to make Chengdu a highly harmonious and unified city form of people, city, environment and industry.

From the above analysis of the connotation of Garden city, we can summarize several characteristics of Garden city: 1. Garden city should be people-centered. Garden city is not a city park, the city is larger than the park, the main body of the city is people, the park is a part of the city, its purpose is to serve the people. Second, we should highlight the ecological value of the city. The theoretical origin of Garden city is closely related to General Secretary Xi Jinping's theory of ecological civilization construction, and strives to achieve the urban greening rate of "open the door to green, go out into the garden". Garden city emphasizes the harmony between man and nature. Garden city requires intensive and efficient production space, moderate living space, beautiful 
ecological space, rich and colorful multi-dimensional integration of human space to build an ecological community of landscape, forests and fields, the core of which is the high integration of human society and nature.

\section{Advantages of the Construction of Garden City for Chengdu}

\subsection{The Existing Urban Planning Is Consistent with the Concept of Garden City}

In 2003, Chengdu began to promote the reform of urban-rural integration. In 2007, Chengdu and Chongqing jointly became the national comprehensive reform pilot area of urban-rural integration. At the end of 2009, Chengdu further proposed to build the world's modern garden city, through the "three-step" strategy, Chengdu will be referred to as a world-class international city, to achieve harmony between man and nature, urban and rural integration of the garden city. Over the years, Chengdu has made some achievements in spatial distribution, industrial restructuring, cultural soft power upgrading, ecological environment improvement, and other aspects. For example, the greenway planning is being implemented, which is consistent with the concept of the garden city, and laid the foundation for the construction of the garden city.

\subsection{Chengdu's Good Ecosystem Provides Natural and Humanistic Ecological Foundation for Construction of Chengdu Garden City}

First, in terms of natural ecological environment, Chengdu has good advantages in mountain, water, field and Lin Fang masks. The ecological base area of Chengdu is more than $80 \%$ of the total area of the city. The mountain areas are mainly Longmen Mountain and Longquan Mountain, which constitute two natural barriers of Chengdu. Chengdu has planned them as Longmen Mountain and Longquan Mountain Ecotourism Comprehensive Functional Zone to make full use of their natural ecological resources. Its reputation is rich in water resources, numerous in water systems, and dense in river networks. To build an urban ecosystem with water as the core is conducive to better reflect the ecological characteristics of the garden city; in the field, Chengdu has fertile soil and is easy to cultivate.

Secondly, in terms of human ecological environment, Chengdu has a profound cultural background and a good cultural brand effect. Chengdu is a famous historical and cultural city. When it comes to Chengdu, people will associate the Three Kingdoms. The Shu kingdom in the Three Kingdoms period has left many historical sites in Chengdu, and has been deeply branded by the three kingdoms. It is not only a city with a long history, but also a leisure city with modern atmosphere. Before 2008, the slogan of Chengdu Promo was "Chengdu is a city that does not want to go when it comes." After the 2008 Wenchuan earthquake, the slogan of Chengdu's promotional film was "Chengdu is better because of you." In 2017, the latest slogan of Chengdu's promotional film was "Chengdu, a bright future for you." Chengdu gives the impression of a leisure city, a vibrant city, a city that conveys positive energy. These are the local cultural ecology of Chengdu's construction Garden city, which is an important manifestation of the core of the people.

\subsection{Chengdu's High-End High-Quality High-Tech Industries Are the Industrial Foundations for Building a Garden City}

Chengdu is a national pilot area for comprehensive innovation and reform, an important national high-tech industrial base, and a pilot city for comprehensive reform of the national service industry. In the list of China's city commercial charm in 2017, Chengdu ranks first in the new tier cities. At the same time, Chengdu, as the strategic frontier for China's opening to the southwest, is an important hub city for the "one belt and one way" strategy, and industrial development is ushering in a major opportunity. Chengdu's GDP reached 138.8939 billion yuan in 2017, accounting for 37.56\% of Sichuan's GDP, and its growth rate has been stable at about $8 \%$ in the past five years. The industrial structure of Chengdu is reasonable. In the tertiary industry, the tertiary industry is the main industry. The tertiary industry in Chengdu has been in a steady growth trend in the past five years, and it 
accounts for more than $50 \%$ of the annual GDP of Chengdu, followed by the secondary industry, accounting for about $40 \%$, while the primary industry accounts for less than $4 \%$. This kind of industrial layout is the unique industrial advantage of Chengdu's Garden city construction, at the same time, it is also the guarantee of maintaining a good ecological foundation.

\section{Suggestions of the Construction of Garden City for Chengdu}

\subsection{Urban planning Adheres to the People Centered Approach}

Adhere to the people-oriented planning, starting from the needs of people, psychological behavior characteristics of space design, to achieve spiritual and material, people and the environment harmony. Starting from the public demand, special planning for urban park system and ecosystem construction should be worked out to integrate Garden city Construction with urban development, enhance Park service, and enhance the scientificity, consistency and systematicness of planning. This is mainly reflected in the following aspects:

First, before conducting project planning, public opinion surveys should be conducted to fully respect the wishes of residents. A project may involve site selection, alteration, new construction and so on, regardless of which content is the focus of concern of stakeholders. For example, whether the project will affect the convenience of existing life, the project will affect the quality of existing living, whether the project is necessary to implement. The goal of Garden city construction is to serve people, and people's needs and feelings are the key factors to determine whether it is necessary and qualified.

Second, in the process of project planning, we should give full consideration to the needs of people's lives and work. According to the garden city concept requirements, the planning to achieve the "open the window visible green, go out visible garden" green ecological goals, park surrounding convenient transportation will encourage people to travel low-carbon. Community culture is integrated with the principle of respecting the people's spontaneity, voluntariness and autonomy as far as possible, and the government mainly guides and guarantees them.

Third, after the completion of the project planning, we should extensively solicit opinions from all sides, and constantly improve and update them. Historically, our city planning has been officially dominated, and there has been less active acceptance of public advice and adoption. The construction of Chengdu Garden city is a long-term project, which should not only have a long-term vision, but also pay attention to the delicacy of the present. Through extensive consultation with the community, we can better avoid unreasonable, inappropriate, unnecessary planning and design, at the same time, in the construction process, keep pace with the times, and constantly improve and supplement.

\subsection{Urban planning should Improve the Index System}

First, the human perspective. To construct the index system from the perspective of human beings, we can start from three dimensions: the satisfaction of the people, the density of the population, and the comprehensive quality of the people. The satisfaction of the people is the satisfaction of the people after the completion of the garden city. The higher the satisfaction is, the more successful it is. Population density is included in the assessment index system, on the one hand, because population density is an important factor affecting the garden city construction, on the other hand, the population density in different areas of the city is different, different density to adopt different planning programs to achieve the best harmonious atmosphere. People's comprehensive literacy includes health literacy and cultural literacy. Health literacy is an important index to measure the ecological environment and medical level of a city. Cultural literacy includes citizen's moral literacy and the proportion of high-end technicians. It is the name card of a city image and the external manifestation of cultural and urban integration.

Secondly, the perspective of the city. It mainly includes the supply of urban infrastructure and public goods. Infrastructure design transportation, water conservancy, electricity, communications, etc. Among them, the traffic can be subdivided into bus platform coverage, bus average waiting time, pavement coverage and so on. The supply of public goods includes education, science and technology, 
culture, security and so on. Education can be subdivided into pre-school education, compulsory education, higher education and vocational education. Among them, pre-school education can be further subdivided into the proportion of pre-school education institutions and school-age children, the ratio of teachers and students in pre-school education.

From the perspective of environment. Environment can start from three dimensions: water, land and air. Water mainly refers to the water quality of rivers, lakes and Jiang Liu. Land is mainly covered by parks' coverage and utilization rate, urban green space ratio, green coverage rate and green sight rate. Air quality is mainly air quality, including the proportion of good weather in an all-round way, the efficiency of controlling greenhouse gas emissions in cities and so on.

Finally, the industry perspective. Industry can be divided into industrial resource, structural, aggregate, innovative and productive forces.

Table 1. Index system of garden park industry

\begin{tabular}{|c|c|}
\hline Item & Indexes \\
\hline $\begin{array}{l}\text { Industrial } \\
\text { resource force }\end{array}$ & $\begin{array}{l}\text { The proportion of high-end technicians employed, urban employment rate, the } \\
\text { proportion of employees with bachelor's degree or above, and the proportion of } \\
\text { renewable energy to basic energy consumption }\end{array}$ \\
\hline $\begin{array}{l}\text { Industrial } \\
\text { structure force }\end{array}$ & $\begin{array}{l}\text { The proportion of the primary industry, the secondary industry and the tertiary } \\
\text { industry to the city's annual gross domestic product and the ratio of the added } \\
\text { value of the high-tech industry to the added value of the industry respectively }\end{array}$ \\
\hline $\begin{array}{l}\text { Industrial } \\
\text { agglomeration } \\
\text { force }\end{array}$ & $\begin{array}{l}\text { The degree of spatial agglomeration, the linkage degree of the same industry, } \\
\text { and the connection degree of different industries. }\end{array}$ \\
\hline $\begin{array}{l}\text { Industrial } \\
\text { Innovation } \\
\text { force }\end{array}$ & $\begin{array}{c}\text { The conversion rate of scientific and technological achievements and the } \\
\text { number of patents granted }\end{array}$ \\
\hline $\begin{array}{l}\text { Industrial } \\
\text { output force }\end{array}$ & $\begin{array}{l}\text { The gross domestic product GDP, per capita GDP, the added value of urban } \\
\text { profits and taxes, and the pass rate of products. }\end{array}$ \\
\hline
\end{tabular}

\subsection{Make Full Use of Existing Resources to Create a Sustainable Urban Ecological Mode}

Here we divide the urban resources into two aspects: "hard" resources and "soft" resources.

In terms of "hard" resources, this paper focuses on the construction of "sponge city" and the utilization of "the fifth elevation". Garden city is a low energy consumption city, encouraging new energy utilization, respecting nature and developing ecological energy system. In the construction, we can take the opportunity of the greenway and the park system to implement the sponge city, enhance the permeability of the city, optimize the microclimate of the place, combine the original ecological background of the existing water system, lakes and wetlands, strengthen the management of urban rainwater and flood, promote the ecological balance of urban water, realize the benign water cycle of the city, and build an ecological intelligent garden city. City. We should actively explore policies such as compensation for building retreat (rewarding the volume rate by taking the first floor of overhead buildings or enlarging the building retreat as public open space), encourage the implementation of three-dimensional greening with emphasis on roofs, building walls and revetments, beautify the "fifth interior" of the city, present a 360-degree three-dimensional greening image of the city, and help "Garden city" City Construction and urban public space increase.

In terms of "soft" resources, this article mainly discusses the cultural characteristics of Chengdu and its integration with the city. Deep excavation of ancient Shu farming culture, Three Kingdoms culture, Western Sichuan folk culture and other regional characteristics of culture, focusing on parks and urban communities in Chengdu into the characteristics of cultural symbols, parks and communities as the carrier, and actively combined with the regional cultural characteristics of Chengdu districts and counties, to create theme cultural parks and neighborhood communities. Based on the existing construction, we should optimize the layout of land use and design high-level large-scale cultural facilities such as museums, science and technology museums, cultural centers and concert halls. At the same time, we should encourage community comprehensive service centers to 
enrich the content of community cultural activities and make them a complex city with ecological, cultural and tourism belts. Humanistic space can truly realize "one district, one characteristic, one park, one theme" and enhance the cultural connotation of garden city.

\section{References}

[1] Sang Dongsheng, Sun Xinghua, Yang Fei, et al. Theoretical and Practical Exploration on Development Model for “Eco-Garden-City” [J]. West Forum, 2014, 24(4): 70-77.

[2] Wang Kai, Zhang Yunfeng. The Connotation and Contemporary Value of the Thought of Garden City-Also on the Target and Path of China's Livable City Project [J]. Frontiers, 2016(7): 6-12.

[3] Huang Yun, Lv Bin. Strategies for Construction of World Modern Garden City in Chengdu City under the Background of Integration of Urban- rural Development [J]. Journal of Anhui Agricultural Sciences, 2011, 39(21): 12944-12946.

[4] Chen Guangyong, Yu Xuelian, Du Yanwei. “The Word Moderm Garden City” Sports Culture Construction and Development Counter Measures of Chengdu Leisure Concept [J]. Sichuan Sports Science, 2014(3): 4-5+23. 